\title{
UNA VISIÓN FILOSÓFICA DE LA UNIVERSIDAD EN EL ÁMBITO DE LA ERA TÉCNICA*
}

\author{
pOr JORGE ACEVEDO GUERRA \\ Director del Departamento de Filosofia, \\ Facultad de Filosofia y Humanidades, \\ Universidad de Chile.
}

Dirección Postal: Casilla 10136, Correo Central, Santiago, Chile.

\section{RESUMEN}

El presente artículo plantea el problema del concepto y rol de la Universidad en la época que se ha dado en llamar moderna, y la consiguiente pérdida de sentido y posición de esta institución fundamental, en los ámbitos material y formal, frente a la avalancha irrefrenable de la era tecnológica de la producción. Ante ello, el autor manifiesta esperanza en que la Universidad pueda recuperar su sitial de "universalidad" en el sentido más profundamente antropológico, atisbando algunas propuestas.

Desde un punto de vista filosófico, es posible abordar el tema de la Universidad de muchas maneras. Un modo fecundo de tratar el problema consistiría en lo siguiente: por una parte, ver la institución universitaria en el contexto de la época moderna; por otra, observar que nuestras Universidades - insertas en el ámbito moderno- tienen como una de sus metas fundamentales el modernizarse cada vez más.

"Trabajo presentado a las "Jornadas de Reflexión sobre las Humanidades". 
No sería oportuno entrar ahora en el debate acerca de la modernidad $y$ de la postmodernidad en forma directa ${ }^{1}$. No obstante, algunos puntos de esa discusión - que hoy se encuentra en primer plano-, irán saliendo a nuestro encuentro en el desarrollo de estas reflexiones.

Se dice en varios círculos intelectuales que la modernidad está finalizando; sin embargo, sólo podríamos aceptar que esa supuesta extinción ocurre exclusivamente en tales círculos - $\mathrm{y}$ en otros semejantes-, con la fuerza que hace imaginar ese aserto. El núcleo de las sociedades occidentales sigue siendo moderno. Más aún: cabe afirmar que en nuestro tiempo la modernidad está en su apogeo, habiendo, frente a ella, meras reacciones débiles en el plano propiamente colectivo.

Para evitar equívocos, debo decir que en mi planteamiento "época moderna" equivale a "era técnica". Siguiendo a Heidegger, dejamos establecido que la era técnica "surgió primero en el siglo xvi y en Europa y sólo en Europa. Durante largo tiempo el resto del globo la desconoció. Les fue totalmente ajena a las anteriores épocas y al destino de sus pueblos"2. La situación actual es, por cierto, totalmente distinta respecto de la del siglo xvI. En efecto, la relación fundamentalmente técnica del hombre respecto del Universo se derramó, desde Europa, en todas las direcciones. Es posible afirmar, por tanto, que hoy todo el planeta vive, prácticamente, en una era tecnológica. Algunos rasgos de la época de la técnica moderna - esto es, de nuestro tiempo-son "la funcionalización, la perfección, la automatización, la burocratización, la información"

Las Universidades - y también, claro está, las hispanoamericanasson instituciones que discurren bajo el pregnante sello de la tecnología, entendiendo esa palabra en el sentido indicado -es decir, el de Heidegger-. Esto implica varias consecuencias, algunas de las cuales someteremos a análisis a continuación.

${ }^{1}$ Por ahora, remito al capítulo III de mi libro La sociedad como proyecto, "Modernidad y postmodernidad. Vida personal e historia, un retorno hacia lo cercano", Editorial Universitaria, Santiago., 1994.

${ }^{2}$ Heidegger, Martin, "Serenidad", en Revista de la Sociedad Argentina de Filosofia, Año V, № 3, p.114, Córdoba, 1985. Traducción de Elbio Caletti y Adolfo P. Carpio (Gelassenheit, Neske Verlag, Pfullingen, 1959, p.20).

${ }^{3}$ Heidegger, Martin, "La constitución onto-teo-lógica de la metafísica", en Revista de Filosofía Vol. xIII, № 1, Santiago, 1966. Traducción de Luis Hernández, revisada por Francisco Soler, p. 100 (Identidad y diferencia, Edición bilingüe, Editorial Anthropos, Barcelona, 1988, Traducción de Helena Cortés y Arturo Leyte, pp. 114-117). 
La concepción del hombre que subyace en el funcionamiento de las Universidades actuales -congruente con la época técnica en que existimos-, lo comprende, predominantemente, como animal de trabajo (arbeitende Lebewesen, arbeitende Tier) ${ }^{4}$, como material humano (Menschenmaterial) $^{5}$ y como señor de la Tierra ${ }^{6}$. Antiguas definiciones antropológicas son parcial o totalmente desplazadas; en cualquier caso, de hecho, no cuentan. Por ejemplo, el hombre como viviente que posee

"Véase, de Heidegger "Superación de la metafísica", en Conferencias y Artículos, Eds. del Serbal, Barcelona, 1994, p. 64, trad. de Eustaquio Barjau ("Überwindung der Metaphysik", en Vorträge und Aufsätze, Neske Verlag, Pfullingen, 1967, vol. I, p. 64. André Préau vierte arbeitende Tier por bête de labeur. Por cierto, esta traducción -que es una perspicaz interpretación (como toda traducción acertada)-, tiene que ser tomada en cuenta. Cfr., "Dèpassement de la mètaphysique", en Essais et conférences, Éditions Gallimard, París, 1966, p. 82).

5Véase de Heidegger "La pregunta por la técnica", en Ciencia y Técnica, Editorial Universitaria, Santiago, 1993 (segunda edición), trad. de Francisco Soler, p. 87 ("Die Frage nach der Technik", en Vorträge und Aufsätze, ed. cit., vol.I, p.17). Juan de Dios Vial Correa -rector de la Pontificia Universidad Católica de Chile-, reafirma esta idea del pensador de Friburgo en el contexto de la antropología cristiana. Dice, sin ambages -y en sus palabras se adelantan planteamientos que bosquejo más adelante-, lo siguiente: "Esa forma de participación en el ser de las cosas que es la técnica y que es la ciencia, tiende espontáneamente a degradarse, a transformarse en una utilización de la realidad, para los fines del hombre, considerándose la primera como disponible para todo lo que se quiera hacer con ella. Esa es la visión o el aspecto con que se presenta la técnica espontáneamente al ser humano durante una buena parte de la edad moderna. Eso fue sintetizado o expresado a la altura de la Primera Guerra Mundial, al referirse a los soldados, al personal del ejército, con la expresión 'el material humano'. Esa formulación realmente innoble dice todo. Incluso el hombre llega a ser un material para el hombre. La fuerza que organiza todo esto, que le da alguna cohesión y consistencia a la sociedad, termina siendo la simple voluntad de poder. [...] Eso constituye verdaderamente una degradación de lo humano y un daño profundo a la vida del hombre". Cfr., "La ciencia, la técnica y los desafios modernos", en revista Humanitas № 1, Santiago, 1996, p. 138.

${ }^{6}$ Conviene tener ante la vista, a propósito de esto, el siguiente texto de Nietzsche: "Vendrá el tiempo en que se conducirá la lucha por el dominio de la tierra en nombre de doctrinas filosóficas fundamentales". El comentario de Heidegger a esas palabras esclarecen su sentido: "Esas 'teorias filisoficas fundamentales' no aluden a las doctrinas de los eruditos, sino al lenguaje de la verdad de lo ente como tal, verdad que es la propia metafísica bajo la figura de la metafisica de la subjetividad incondicionada de la voluntad de poder". Véase, de Heidegger, "La frase de Nietzsche 'Dios ha muerto' ", en Caminos de bosque, Editorial Alianza, Madrid, 1995, trad. de Helena Cortés y Arturo Leyte, p. 231 [Sendas Perdidas, Editorial Losada, Buenos Aires, 1960, p. 214] ("Nietzsches Wort 'Gott ist tot', en Holzwege, V. Klostermann, Frankfurt a. M., 1950, pp. 236 y ss.). 


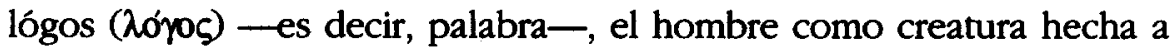
imagen y semejanza de Dios, el hombre como ingrediente de una estructura que lo contiene dentro de sí, y de la que no puede disponer a voluntad.

Aunque no siempre sea esto evidente, la idea del hombre que funciona como supuesto de las Universidades modernas determina sus metas, su estructuración y, en general, todas sus dimensiones.

Por lo pronto, el carácter radicalmente técnico de nuestra época tiende a constituir a la Universidad como un dispositivo tecnológico semejante a una fábrica, una factoría, un complejo industrial, una entidad financiera. La gestación, la gestión, las relaciones humanas dentro de ella, propenden a igualarse con las de los demás dispositivos tecnológicos de la sociedad. Poco a poco, la Universidad va dejando de ser un poder espiritual - a veces, decisivo- dentro de la nación. El concepto de Universidad como alma máter, madre nutricia, pasa a segundo plano o se desvanece por completo.

La institución tiene ahora la misión básica de formar al animal del trabajo, es decir, producir eficientes productores y, en consonancia con ello, buenos consumidores. Para alcanzar este objetivo, los universitarios son adiestrados, ante todo, en el pensamiento técnico, calculador o computante, entendiendo estos calificativos en sentido amplio. En efecto, este tipo de pensar no se reduce a operar con números o a manejar aparatos de cálculo automático; va más allá, y abarca todos los sectores de la realidad. Heidegger lo caracteriza, de manera apretada, en estos términos: "Su peculiaridad consiste en que cuando planificamos, investigamos, organizamos una empresa, contamos ya siempre con circunstancias dadas. Las tomamos en cuenta con la calculada intención de unas finalidades determinadas. Contamos de antemano con determinados resultados. Este cálculo caracteriza a todo pensar planificador $\mathrm{e}$ investigador. Semejante pensar sigue siendo cálculo aun cuando no opere con números ni ponga en movimiento máquinas de sumar ni calculadoras electrónicas. El pensamiento que cuenta, calcula; calcula posibilidades continuamente nuevas, con perspectivas cada vez más ricas y a la vez más económicas ${ }^{7 ”}$.

${ }^{7}$ Heidegger, Martin, Serenidad, Ediciones del Serbal, Barcelona, 1989. Traducción de Ives Zimmermann (Gelassenheit, pp. 14 y ss.). Véase, también de Heidegger, "Ciencia y Meditación", en Ciencia y Técnica, ed.cit., pp. 125 y ss. ("Wissenschaft und Besinnung", en Vorträge und Aufsätze, ed.cit. tomo I, pp. 50 y ss.). 
A través del adiestramiento en el pensar computante, el animal del trabajo -esto es, el hombre-, se convierte en un material humano apropiado para rendir el máximo en el proceso de la producción, proceso que, en los días que corren, hace de hilo conductor de nuestra existencia histórica ${ }^{8}$. Así como otros establecimientos de enseñanza preparan una "mano de obra" eficiente, las Universidades se encargan de los "cerebros de obra". A través de uno u otro camino se llega a lo mismo: a ensamblar eficaces equipos de "material humano".

Pero el pensamiento calculador tiene otros rasgos. Uno de ellos induce al hombre a adoptar actitudes despóticas frente a la naturaleza y frente a sí mismo. Como se ha dicho en innumerables ocasiones -aunque sin descender, en la mayoría de los casos, hacia un terreno filosófico-, la conducta del hombre moderno ante su contorno natural es la de un depredador. Los ríos y mares, las montañas y desiertos, el suelo y el aire, la fauna y, particularmente, él mismo, son convertidos por el hombre de la técnica en parámetros de su proyecto de conquista y explotación incondicionadas de todo lo real. Hay múltiples fenómenos, bien precisos, que ilustran lo que digo. Todos conocemos los peligros entrañados en la construcción de una central hidroeléctrica en una corriente de agua, o los que conlleva la eliminación de desechos en los procesos industriales, o los que están ínsitos en el transporte marítimo del petróleo, o en la utilización de la energía atómica con fines pacíficos. Todos sabemos también que estos peligros que nos amenazan no han sido suficientemente controlados, ni parece que lo vayan a ser en un futuro próximo, a pesar de la férrea voluntad que poderosas organizaciones ponen en lograrlo. El presunto señor de la Tierra - el hombre moderno- no lo es tanto; a veces, y por doquier, tropieza con sorprendentes reacciones de aquello que quiere dominar - la naturale$\mathrm{za}$-, reacciones que lo dañan y desconciertan'. El proyecto de Bacon -obedecer a la naturaleza para ponerla al servicio del hombre-, junto a un brillante anverso (que podemos y tenemos que reconocer plenamente como tal), está mostrando un oscuro reverso.

${ }^{8}$ Ortega y Gasset, José, 'Una vista sobre la situación del gerente o 'manager' en la sociedad actual", en Pasado y porvenir para el hombre actual, Obras Completas, vol x, Ediciones Revista de Occidente, Madrid, 1965, pp. 728 y 742.

${ }^{9}$ Acevedo, Jorge, "Esbozo de la interpretación de la naturaleza en la obra de Martin Heidegger", en Káñina (Revista de Artes y Letras de la Universidad de Costa Rica), Vol. XVII, № 1, San José, 1993, pp. 183 y ss. 
En correspondencia con la concepción del hombre y la interpretación del pensamiento dominantes en nuestra época $-y$, por tanto, dentro de las Universidades-, predomina hoy una posición axiológica que pone como valor supremo la eficacia incondicionada en el funcionamiento de los dispositivos tecnológicos -entre los que se incluye, como uno más, la Universidad-. Este "valor supremo" exige el ejercicio deliberado y sistemático de la competitividad con los otros y con uno mismo. Eficacia incondicionada y competitividad a ultranza se erigen como criterios últimos de jerarquización, ordenación y evaluación de los dispositivos tecnológicos - uno de los cuales es la Universidad-, y de sus componentes —entre los que está el hombre, como material humano-. Por cierto, esta situación axiológica —que reina en la Universidad y que se potencia a través de ella-, choca frontalmente con casi todas las tablas de valores que se han propuesto explícitamente en la historia de la Humanidad. Al respecto, baste con recordar la difundida postura de Max Scheler, dentro de la filosofia, o la que hallamos en los Evangelios, en el ámbito de la religión ${ }^{10}$

Todo lo que, en lo anteriormente expuesto, parece ser peyorativo, no lo es en verdad. Tampoco hay en lo dicho una crítica moral a los que participamos en la organización de los dispositivos tecnológicos universitarios o a los que, simplemente, forman parte de ellos. Nuestras conductas, en cuanto universitarios, se limitan a corresponder y a obedecer al "espíritu del tiempo", el cual, hay que advertirlo, es insoslayable en primera instancia ${ }^{11} \mathrm{y}$, tal vez, en varias más. No está en nuestra mano - ni en la de ningún hombre o grupo humano- sustraernos por completo al sello radicalmente técnico de la época que nos ha tocado vivir. Al describir algunos rasgos epocales de las Universidades no se están repartiendo culpas. La misión tecnocrática que, de hecho, ha asumido la Universidad actual, no es responsabilidad de nadie determinado. Se trata de algo que responde a las corrientes más profundas de la marcha histórica de Occidente.

¿Debemos, pues, aceptar, sin más, que el sello técnico de la Universidad contemporánea determine todo lo que a ella atañe? ¿La organización de las Facultades, las relaciones interpersonales o de grupos, los

\footnotetext{
${ }^{10}$ Una elaboración reciente de las cuestiones axiológicas puede encontrarse en la segunda parte - "Hombre y Valor" - de Conciencia y Mundo, de Cristóbal Holzapfel, Ediciones de la Universidad Nacional Andrés Bello, Santiago, 1993, el que he comentado en la Revista de Filosofía, Vol. xt.III-xtrv, Santiago, 1994.

${ }^{11}$ Quizás habría que decir "en última instancia".
} 
programas académicos, los planes de estudios, la asignación de presupuestos tendrían que plegarse dócilmente a la impronta técnica de las Universidades modernas? No creo que así sea. ¿Qué se requeriría, entonces, para que la Universidad vuelva a ser - sin radicales restricciones, como ahora- el alma máter, la madre nutricia que alguna vez fue? ¿Qué se necesitaría para que las Universidades vuelvan a constituirse en un genuino y aceptado "poder espiritual"? ¿Qué habría que hacer para que estos dispositivos tecnológicos formaran hombres cultos, seres humanos que estuvieran, en el más pleno sentido de esta expresión, a la altura de los tiempos?

Sería presuntuoso de nuestra parte querer presentar algo así como una fórmula que, mágicamente, "retrotrajera" a la Universidad a su auténtica esencia - en vez de "retrotraer" podríamos hablar de proyectar, ya que no se trata de sugerir ninguna "vuelta atrás"-y la albergara frente a las des-composturas introducidas en ella por la tecnología, es decir, por la metafisica de la era atómica ${ }^{12}$. No obstante - siguiendo a Heidegger ${ }^{13}$-, podemos sugerir algunos caminos a través de los que se podría avanzar hacia lo prístino de la Universidad.

Por lo pronto, tendría que alcanzarse una comunidad lingüistica mínima que permitiera entenderse cuando se habla de los asuntos universitarios. La fragmentación de la Universidad -que ha dado lugar a una situación babélica respecto de ella - fue puesta de relieve por este pensador ya en 1929, y reiterada por él mismo en ocasiones posteriores, cuando se le interrogaba sobre la misión de la Universidad ${ }^{14}$. En la

${ }^{12}$ Respecto de esta acepción del término "tecnología", véase, de Heidegger, "La constitución onto-teo-lógica de la metafísica", en Revista de Filosofía, Vol. xII, № 1, Santiago, 1966, p.100 (Identidad y Diferencia, ed.cit., pp. 116 y ss.).

${ }^{13}$ Habría que hacer notar que ni a partir de este pensador ni a partir de ningún otro sería posible llegar a una enmienda fácilmente manejable acerca de lo planteado. El mismo Heidegger ha advertido - no sólo frente a este tipo de situaciones, sino frente a otras más graves y radicales, base de las anteriores- que "hoy está especialmente cercana la tentación de estimar la discresión [Bedachtsamkeit: lentitud] del pensar por el tiempo del cálculo y de la planificación, que justifica inmediatamente en cualquiera sus hallazgos técnicos por el éxito económico. Esta depreciación del pensar le sobreexige con módulos que le son extraños. Al mismo tiempo, se le supone al pensar la pretención arrogante de saber la solución de los enigmas y de traer la salvación". Cfr., "Hacia la pregunta del ser", en Acerca del nibilismo, Paidós I.C.E. | U.A.B., Barcelona, 1994, trad. de José Luis Molinuevo, p. 101. [Sobre la cuestión del ser, Ed. Revista de Occidente, Madrid, 1958, trad. de Germán Blaeiberg; p. 45] ("Zur Seinsfrage" (1956), en Wegmarken, V. Klostermann, Frankfurt a. M., 1967, p. 234).

${ }^{14}$ Así, por ejemplo, en la entrevista que concedió a Richard Wisser, el 24 de 
conferencia “¿Qué es metafísica?”, decía: "Los dominios de las ciencias están muy distantes entre sí. El modo de tratar sus objetos es radicalmente diferente. Esta dispersa multiplicidad de disciplinas se mantiene, todavía, unida gracias tan sólo a la organización técnica de las Universidades y Facultades, y conserva una significación por la finalidad práctica de las especialidades. En cambio, el enraizamiento de las ciencias en su fundamento esencial se ha perdido por completo"15. Superar el desarraigo de las ciencias y su falta de unidad implicaría, me parece, dirigir una primera y decisiva mirada hacia la Filosofía, para buscar alli el lugar de inserción de cada una de ellas en su fundamento esencial, de tal modo que - más allá, o más acá, de las discrepancias que pudieren haber al debatir sobre la Universidad- un economista y un filólogo, un historiador y un físico, un jurista y un fisiólogo, un matemático y un lingüista, un pintor y un geógrafo se comprendieran en lo básico. Como me indicaba un respetado amigo - experto tanto en el plano de los principios como en los de la efectiva organización y orientación de la Universidad-, sin alcanzar una comunidad en el lenguaje —que supondría la vigencia de una experiencia común ${ }^{16}$, el diálogo intrauniversitario se torna imposible o inútil. Por cierto, la conversación entre la Universidad y sus interlocutores externos ostentaría en esa situación -que es la que estamos viviendo- esas mismas características acentuadas (No se me ocultan las dificultades - tal vez insuperables en lo inmediato- que obstaculizan el camino hacia la

septiembre de 1969 - con motivo de cumplir ochenta años-, la que fue transmitida por la segunda cadena de la televisión alemana. Cfr., de Richard Wisser, Martin Heidegger al babla, Eds. STVDIVM, Madrid, 1971, pp.71 y ss., trad. de Rafael Ángel Herra (Martin Heidegger im Gespräch; herausgegeben von Richard Wisser. Verlag Karl Alber, Freiburg/München, 1970, pp. 67 y ss.). Así, también, en la conversación con Der Spiegel, del 23 de septiembre de 1966, publicada póstumamente bajo el título "Ya sólo un Dios puede salvarnos". Cfr., revista Escritos de Teoria, II, Santiago, 1977, pp. 174 y ss., trad. de Pablo Oyarzún ("Nur noch ein Gott kann uns retten", revista Der Spiegel № 23, Hamburg, 1976, p. 196).

${ }^{15}$ Ediciones Siglo Veinte, Buenos Aires, 1967, p.77. Traducción de Xavier Zubiri ("Was ist Metaphysik?", en Wegmarken, Vittorio Klostermann, Frankfurt a. M., 1967, p. 2).

${ }^{16}$ Sobre el decisivo concepto de "experiencia común", remito al libro de Humberto Giannini La reflexión cotidiana. Hacia una arqueología de la experiencia, Editorial Universitaria, Santiago, 1987. He comentado esta relevante obra - traducida al francés con 'Prólogo' de Paul Ricoeur-, en la revista Opciones, № 13, Santiago, 1988, pp. 201 y ss., y en la Revista Chilena de Humanidades, № 10, Santiago, 1988, pp. 23 y ss.). 
comunidad de experiencia y de lenguaje a la que aludo. Espero referirme a ellas en otra ocasión).

Luego $\longrightarrow$, más bien, simultáneamente, puesto que hay un vínculo primordial entre lo que he planteado antes y lo que digo a continuación-, habría que recordar y asumir enérgicamente el carácter multidimensional del hombre. Éste no es sólo, ni principalmente, animal del trabajo, material humano - mano de obra o cerebro de obra-, o déspota de lo real en su totalidad. Ante todo, es también -y con esto no pretendo agotar la esencia del hombre-, el viviente poseído por el lógos ( $\lambda$ óyos) — mas bien que "poseedor" de la palabra ${ }^{17}$-; es alguien único de dignidad superior, es un ser limitado y finito - y este rasgo lo asemeja a todas las demás realidades-.

Empuñar con la debida fuerza la multilateralidad del hombre ${ }^{18}$ exigiría, pues, entre otras cosas, cultivar la palabra en su más alta manifestación, esto es, como Poesía, entendiendo este término en su más amplio y elevado sentido, que incluye tanto a la Filosofia - la Protopoesía ${ }^{19}$ como a la Literatura. Exigiría, también, equilibrar el ejercicio del pensar computante -que pretende erigirse como la única manera de pensar válida - con la puesta en juego de un pensar que llamaremos meditativo, el que no se limita a calcular con vistas al éxito, sino que discurre

${ }^{17}$ Véase, de Heidegger, "Construir Habitar Pensar"; en Ciencia y Técnica, ed. cit., pp. 160 y ss. ("Bauen Wohnen Denken", en Vorträge und Aufsätze, ed. cit., vol. II, p. 20 ). Del mismo Heidegger, De camino al babla, Eds. del Serbal, Barcelona, segunda ed. revisada, 1990, trad. de Yves Zimmermann (Unterwegs zur Spracbe, Verlag Günther Neske, Pfullingen, 1959. El primer ensayo de esta obra - "Die Sprache", "El habla"-, ha sido traducido, también, por Francisco Soler, y publicado en la Revista de Filasofía Vol. viI, Nos. 2-3, Santiago, 1961).

${ }^{18}$ Recordemos, a propósito de esto, por una parte, que Dilthey descubrió que "la vida es 'eben mehrseitig'; que la vida es 'precisamente multilateral', que es siempre 'lo uno y lo otro', es decir, lo más radical del fenómeno vida es su carácter equívoco, su sustancial problematicidad. De ahi viene todo" (Cfr., de Ortega, La idea del principio en Leibniz, y La evolución de la teoría deductiva; Obras Completas, Vol. ViI, p. 297. Por otra, que "la verdadera 'entereza', la Gründlichkeit, no consiste en entregarse a sólo una cosa, sino en ser todas las que resulten precisas" (Véase, de Ortega, Un rasgo de la vida alemana, en Obras Completas, Vol. v, p. 191).

${ }^{19}$ Acerca del pensar como poetizar, véase, de Heidegger, "El dicho de Anaximandro", en Caminos de Bosque, Alianza Editorial, Madrid, 1995, p. 297. Traducción de Helena Cortés y Arturo Leyte (Sendas Perdidas, Editorial Losada, Buenos Aires, 1960, p. 275; "Der Spruch des Anaximander", en Holzwege, Vittorio Klostermann, Frankfurt a. M., 1950, p. 303). 
tras el sentido de todo acontecer. Exigiría, además, que el hombre cuide y proteja las realidades que le rodean, a sus semejantes - mortales, como él- y a sí mismo, desplegando un fervoroso respeto por todo ello, y "renunciando" a implantarse como amo irrestricto de cuanto hay.

Si ocurriera esa transformación en lo que - de manera lata-podríamos denominar "supuestos antropológicos" de la Universidad, acaecería un vuelco axiológico en la base de la institución. Los valores supremos no serían ya la eficacia incondicionada de los dispositivos tecnológicos ni su competitividad a ultranza, sino que tales valores -en la medida en que lo sean-, tendrian que conjugarse con otros y supeditarse a ellos, como la solidaridad ${ }^{20}$ y la serenidad, entendiendo este último vocablo en el sentido que le asigna Heidegger, es decir, como una actitud en virtud de la cual nos insertamos convenientemente en los dispositivos tecnológicos, evitando que la mecánica de su funcionamiento nos dañe, nos aplaste, nos triture o nos devaste.

Luego de esa transvaloración, tal vez la Universidad quedaría en condiciones de transfigurarse -en la medida en que una institución social pueda llegar a ser algo así- en un "poder no violento"21, tanto hacia dentro de ella misma como respecto del contorno colectivo que la envuelve, hacia el cual irradiaría la nueva postura estimativa. Así, también, la Universidad —quizás ya digna de ese nombre sin restriccio-

${ }^{20}$ Unas palabras de Octavio Paz (quien habla de fraternidad para referirse a la solidaridad), recogidas por Agustín Squella Narducci, rector de la Universidad de Valparaíso, pueden ayudar a recordarnos el sentido de este término y de la actitud correspondiente, que parece habérsenos escapado de un tiempo a esta parte. En una entrevista, después de indicar que ha "criticado al socialismo (o lo que se ha hecho pasar por tal)", agregó: "Ahora déjeme decirle que al liberalismo actual le faltan muchas cosas, sin las cuales la vida no es digna de ser vivida. Si pensamos en aquella tríada con la que comienza el mundo moderno, la libertad, igualdad y fraternidad, vemos que la libertad tiende a convertirse en tiranía sobre los otros; por lo tanto, tiene que tener un límite; la igualdad, por su parte, es un ideal inalcanzable a no ser que se aplique por la fuerza, lo que implica despotismo. El puente entre ambas es la fraternidad, la gran ausente en las sociedades democráticas capitalistas. La fraternidad es el valor que nos hace falta, el eje de una sociedad mejor. Nuestra obligación es redescubrirla y ejercitarla". (Véase, ¿Que be aprendido enseñando filosofia del derecho?, EDEVAL, Valparaíso (Chile), 1995, p. 51). Hago esta referencia al término solidaridad porque, al igual que la expresión poder espiritual -a la que aludo más adelante-, ha quedado vacío de sentido, y, como sugiere Paz, urge recuperarlo.

${ }^{21}$ Acerca de esta expresión, véase, de Heidegger, "Ya sólo un Dios puede salvarnos", en revista Escritos de Teoria II, Santiago, 1977, p. 184. ("Nur noch ein Gott Kann uns retten", en revista Der Spiegel, № 23, 1976, p. 209). 
nes- podría presentársenos de nuevo como factor decisivo, en tanto poder espiritual ${ }^{22}$, de la marcha de la historia. Acaso habría recuperado su más propia posibilidad, su misión más genuina ${ }^{23}$.

${ }^{22} \mathrm{El}$ concepto de espiritu (Geist) es sobremanera problemático; así lo ha hecho notar Ortega en los capítulos VI y VII de Historia como sistema (O. C., vol. vi). No obstante, podemos hallar importantes esclarecimientos al respecto en la Introducción a la Metafísica, de Heidegger (Ed. Nova, Buenos Aires, 1959, trad. de Emilio Estiú, pp. 82. Ed. Gedisa, Barcelona, 1993, trad. de Ángela Ackermanin, pp. 49 y ss. [Einfübrung in die Metaphysik, Max Niemeyer Verlag, Tübingen, 1957, pp. 34 y ss.J). Tales aclaraciones pueden permitir que la expresión poder espiritual se torne controlable. Por ahora, destaco estos dos textos: 1 . "Frente a la complejidad de interpretaciones erróneas del espíritu, determinamos su esencia brevemente así [...]: 'El espíritu no es hueca sagacidad ni sutil juego sin compromisos del ingenio, ni tampoco desmesurado impulso de análisis intelectuales ni, menos aún, la razón universal, sino que consiste en la desición, originariamente acordada, de estar abierto a sabiendas a la esencia del ser [Geist ist ursprünglich gestimmte, wissende Entschlossenheit zum Wesen des Seins\}'". 2. "Si se quiere llamar Universidad a la institución en la que se encadenan las ciencias especializadas, tanto desde el punto de vista de la teoría como de la investigación, ello sólo será un nombre, pero ningún poder unificante originario, ninguna fuerza espiritual obligatoria" (Ed. Nova, pp. 86 y 87, Ed. Gedisa, pp. 52 y 53; Ed. Alemana, pp. 37 y ss.).

${ }^{23}$ Respecto del contexto de la posición que he planteado, véase mi libro En tormo a Heidegger, Editorial Universitaria, Santiago, 1990. También "Notas sobre el origen de la actitud filosófica, la cultura y la Universidad", artículo que publiqué en la revista Comunicación y Medios, № 6, Santiago, 1988. 